\title{
Diversion of Constant Crossover Rate DE\BBO to Variable Crossover Rate DE\BBO\L
}

\author{
Ekta $^{1}$, Mandeep Kaur ${ }^{2}$ \\ ${ }^{1}$ Department of Computer Science, GNDU, RC, Jalandhar \\ ${ }^{2}$ Department of Computer Science, GNDU, RC, Jalandhar \\ ${ }^{1}$ er_ekta@yahoo.com, ${ }^{2}$ mandeep8@gmail.com
}

\begin{abstract}
$D E \backslash B B O$ is the combination of differential evolution and biogeography based optimization algorithm to get a better optimization algorithm in terms of convergence speed. In DE\BBO, constant crossover rate has been used which sometimes affect the performance of the hybrid algorithm leading to increase in convergence speed. To cope up with this problem, variable crossover rate has been introduced in the hybrid algorithm helping in removing the problem of constant crossover rate. Modified algorithm has been named as $D E \backslash B B O \backslash$ in which local search mutation and variable crossover rate are used. Testing of $B B O, D E \backslash B B O \backslash$ rand $\wedge 1$ and $D E \backslash B B O \backslash L$ has been performed on different test functions. The results reveal that $D E \backslash B B O \backslash L$ with variable crossover rate is better than DE BBO with constant crossover rate.
\end{abstract}

Keywords: Optimization, Mutation, Differential evolution, Biogeography Based Optimization

\section{Introduction}

Differential evaluation proposed by Storn and Price is parallel direct search way of optimization. The principle of DE lies in generating the trial vector by using some mutation method [1-3]. The basic mutation technique is addition of weighted difference of two population vectors with the third population vector. The resulting vector is checked against the objective function to take decision of keeping or rejecting this vector. There are various mutation methods. Equations of some mutation methods [4] are as given below:

DElrand $\backslash: \mathrm{D}_{\mathrm{i}, \mathrm{G}}=\mathrm{X}_{\mathrm{r} 1, \mathrm{G}}^{\mathrm{i}}+\mathrm{F}\left(\mathrm{X}_{\mathrm{r} 2, \mathrm{G}}^{\mathrm{i}}{ }^{-} \mathrm{X}_{\mathrm{r} 3, \mathrm{G}}^{\mathrm{i}}\right)$

DElBestl1: $\mathrm{D}_{\mathrm{i}, \mathrm{G}}=\mathrm{X}_{\text {best }, \mathrm{G}}+\mathrm{F}\left(\mathrm{X}_{\mathrm{r} 1, \mathrm{G}}^{\mathrm{i}}{ }^{-} \mathrm{X}_{\mathrm{r} 2, \mathrm{G}} \mathrm{i}\right)$

DElBest 2: $D_{\mathrm{i}, \mathrm{G}}=\mathrm{X}_{\text {best }, \mathrm{G}}+\mathrm{F}\left(\mathrm{X}_{\mathrm{r} 1, \mathrm{G}}^{\mathrm{i}}{ }^{-} \mathrm{X}_{\mathrm{r} 2, \mathrm{G}}{ }^{\mathrm{i}}\right)+\mathrm{F}\left(\mathrm{X}_{\mathrm{r} 3, \mathrm{G}}{ }^{\mathrm{i}} \mathrm{X}_{\mathrm{r} 4, \mathrm{G}}^{\mathrm{i}}\right)$

Where $\mathrm{D}_{\mathrm{i}, \mathrm{G}}$ is known as donor vector which is used to modify the target vector $\mathrm{X}_{\mathrm{i}, \mathrm{G}}$. The other vectors are randomly chosen from the population.

Biogeography Based optimization [5] has been influenced from the distribution of species in geographical area. The geographical area has many habitat, some habitat have good features for living beings to be lived whereas some have not. Habitat Suitability Index (HSI) is used to characterize various habitats and Suitability Index Variables (SIV) decides the HSI. Same way has been used in case of optimizing the real world problems. Solutions of the problem are considered as population and their goodness is decided on the basis of the value of the HSI. Immigration and emigration rates are used to modify the various solutions.

The main reason behind the development of the hybrid Differential evolution with Biogeography Based Optimization is the convergence speed of the original BBO. Mutation scheme of DE combined with the $\mathrm{BBO}$ algorithm solves the problem of convergence speed. DELBBO, proposed in 2010, uses the mutation scheme with constant crossover rate which has to be adjusted according to the problem and in some cases, 
constant crossover rate leads to increase in the convergence speed. Modified DE\BBOLL with variable crossover rate solves this problem.

Rest of the paper has been organized as Section 2 gives the view of literature survey. Section 3 describes the modification done in the existing DElBBO. Section 4 shows the results and paper has been concluded in Section 5 giving future scope.

\section{Related Work}

In 2008, Biogeography based optimization method [5] was introduced by Dan Simon. This method has been inspired from the natural way of distribution of species in geographical area. The idea of specie's migration from one habitat to another on the basis of suitability of that particular habitat has been utilized to improve the quality of solutions. Original BBO has many deficiencies. To improve original BBO, many other versions of BBO have been introduced. Oppositional BBO [6] was introduced in 2010, which is focused on improving the convergence speed by using only migration not mutation. Real coded BBO [7] was introduced in 2010, which uses modified mutation operators to improve the performance of original BBO.DE/BBO [8] was introduced in 2010, which provides better robustness and increased convergence speed. Blended BBO [9] was introduced in 2012, which focuses on new way of changing the features of solution. Multiobjective BBO [10] was introduced in 2012, which is based on predator-prey approach. Hybrid BBO [11] was introduced in 2014, which introduces the combination of various evolutionary algorithms with BBO. Linearized BBO [12] was introduced in 2014 for highly non-separable problems.

In 1995, Differential Evaluation optimization method [1] was introduced by Stron R and Price K. In this, trial vector is generated from three vectors randomly selected from the population followed by crossover and selection process. The limitation of DE is premature convergence which has been improved by changing its mutation operator and introducing modified crossover processes. Various modified mutation schemes are DElbest 1 , DEltarget-to-bestlt, DElbest 2 , DElrand 2 etc. Recent work on modification in mutation scheme has been found in 2012 and 2014 which focus on local search mutation [13]. This leads to improvement of the performance of DE in various means like efficiency, quality of solution and robustness.

DE\BBO [8] is based on mutation of differential evolution introduced in BBO algorithm. In this paper, mutation techniques used are based on the use of constant crossover factor for all the generations. Recent mutation technique has been surveyed named as Local search mutation [13] which uses the varying value of CR for each generation. In this, following of good solutions and avoidance of bad solutions has been used. In 2014, RDEL (Restart Differential Evolution algorithm with Local Search Mutation for global numerical optimization) [13] was proposed which solves the problem of choice of $\mathrm{CR}$ value for varying application. In this technique, there is no need of selecting the value of CR. CR is calculated for every generation and this do not lead to influence the convergence speed of the algorithm. Local search mutation has been introduced to improve the convergence speed. This mutation is based on the position of best member and worst member of the population which is inspired from PSO. The idea of learning lies behind the position of best member and worst member of the population. This mutation technique can be illustrated from the following equation:

New Vector $=$ Member chosen at random from population + F1 (Best Member Member chosen at random from population)+ F2( Member chosen at random from population - Worst member)

After mutation, restart mechanism is applied according to the pre-defined criteria.

\section{Modified Hybridization of DE/BBO}


As observed in literature survey, DELBBO uses the mutation techniques with constant $\mathrm{CR}$ value. Hybridization of $\mathrm{DE}$ and $\mathrm{BBO}$ is based on the concept of using the exploration ability of DE and exploitation ability of BBO. When goodness of both is combined, $\mathrm{DE} \backslash \mathrm{BBO}$ outperforms the $\mathrm{BBO}$ in terms of convergence speed. Algorithm 1 describes the process of hybrid migration of $\mathrm{DE} / \mathrm{BBO}[8]$ as given below:

a. for $\mathrm{G}=1$ to GL // GL is generation limit.

b. for $\mathrm{n}=1$ to $\mathrm{PS} / / \mathrm{PS}$ is population size.

c. Randomly select three members so that $\mathrm{a}_{1 \neq} \mathrm{a}_{2 \neq} \mathrm{a}_{3 \neq} \mathrm{n}$

d. $\mathrm{q}_{\mathrm{rand}}=\operatorname{randi}(1, \mathrm{~m}) / /$ randi is used to choose random integer from given numbers.

e. for $\mathrm{q}=1$ to $\mathrm{m} / / \mathrm{m}$ is population dimension.

f. if rand $<\lambda_{n} \quad / / \lambda$ is immigration rate.

g. if $\operatorname{rand}_{\mathrm{q}}>\mathrm{CR}$ or $\mathrm{q}==\mathrm{q}_{\text {rand }} \quad / / \mathrm{CR}$ is crossover rate.

h. $J_{\mathrm{n}}(\mathrm{q})=\mathrm{X}_{\mathrm{a} 1}(\mathrm{q})+\mathrm{F}\left(\mathrm{X}_{\mathrm{a} 2}(\mathrm{q})-\mathrm{X}_{\mathrm{a} 3}(\mathrm{q})\right) / / \mathrm{F}$ is scaling factor.

i. else

j. Randomly select $X_{h}$ with probability $\mu_{\mathrm{h}}$

k. $J_{n}(q)=X_{h}(q)$

1. end

m. else

n. $J_{n}(q)=X_{n}(q)$

o. end

p. end

q. end

r. end

In the above algorithm, $\mathrm{CR}$ and $\mathrm{F}$ are the constants used in differential evaluation optimization where $\mathrm{CR}$ is crossover rate varying from 0 to 1 and $\mathrm{F}$ is scaling factor varying from 0 to 2 . This algorithm describes migration process which is the combination of mutation of differential evaluation and migration of biogeography based optimization.

Algorithm 1 has limitation of increase in convergence rate when CR value tends to its upper limit and CR value is same for all generations. To improve this limitation, Modified DEIBBOIL has been proposed with use of Local search mutation. Local search mutation is based on the concept that good solutions should be adopted and bad solutions should be rejected to inherit the features [13]. The CR value is different for each generation. It does not lead to increase in convergence speed, even if $\mathrm{CR}$ tends to approach its upper limits [13]. Algorithm 2 describes the concept of Modified DEIBBO $\backslash L$ as given below:

a. for $\mathrm{G}=1$ to $\mathrm{GL} / / \mathrm{GL}$ is generation limit.

b. Calculate $\mathrm{CR}=0.8+(0.1-0.8) \cdot(1-\mathrm{G} / \mathrm{GL})^{\wedge} 4 / / \mathrm{CR}$ is crossover rate.

c. for $\mathrm{n}=1$ to $\mathrm{PS} / / \mathrm{PS}$ is population size.

d. Calculate $\mathrm{F} 1=\operatorname{rand}(0,1), \mathrm{F} 2=\operatorname{rand}(0,1)$ and $\mathrm{F} 3=\operatorname{rand}(0,1)$

e. Randomly select three members so that $\mathrm{a}_{1 \neq} \mathrm{a}_{2 \neq} \mathrm{a}_{3 \neq} \mathrm{n}$

f. $\mathrm{q}_{\mathrm{rand}}=\operatorname{randi}(1, \mathrm{~m})$

g. for $\mathrm{q}=1$ to $\mathrm{m} / / \mathrm{m}$ is population dimension.

h. if $\operatorname{rand}_{\mathrm{q}}<\mathrm{CR}$ or $\mathrm{q}==\mathrm{q}_{\text {rand }}$

i. $\quad$ if rand $=(1-\mathrm{G} / \mathrm{GL})$

j. $\quad J_{n}(q)=X_{a 1}(q)+F 1\left(X_{\text {best }}-X_{a 1}(q)\right)+F 2\left(X_{a 1}(q)-X_{\text {worst }}\right)$

k. else

1. $\mathrm{J}_{\mathrm{n}}(\mathrm{q})=\mathrm{X}_{\mathrm{a} 1}(\mathrm{q})+\mathrm{F} 3\left(\mathrm{X}_{\mathrm{a} 2}(\mathrm{q})-\mathrm{X}_{\mathrm{a} 3}(\mathrm{q})\right)$

m. end

n. else

o. $\quad \mathrm{J}_{\mathrm{n}}(\mathrm{q})=\mathrm{X}_{\mathrm{n}}(\mathrm{q})$

p. end

q. end 
r. end

s. end

\section{Experimental Results}

Evaluation of BBO, DE\BBO\rand 1 and DE\BBO $\backslash L$ has been done by using MATLAB software R2012b. The features of the used system are Window 7, RAM 3 GB and Intel i3 processor. Table 1 shows how convergence speed increases with increase in value of constant crossover rate. Table 1 also shows the convergence speed of $\mathrm{BBO}$ and DE $\backslash B B O L L$. In DE $\backslash B B O L L$, crossover rate is not fixed to one value. It goes on changing over generation to generation without affecting the convergence speed. The results have been tested on 10 different test functions by taking the best result among many simulations for each test function.

Figure 1 to Figure 25 shows the convergence characteristics of BBO, DElBBOlrand 11 and $\mathrm{DE} \backslash \mathrm{BBO} \backslash \mathrm{L}$ for different test functions.

\section{Table 1. Convergence Speed in Seconds of BBO, BBO \DE\rand $\backslash 1$ and BBOIDE\L}

\begin{tabular}{|c|c|c|c|c|c|}
\hline 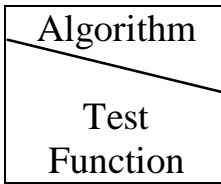 & $\mathrm{BBO}$ & $\begin{array}{l}\text { BBO\DE\rand } \backslash 1 \\
\text { And } C R=0.01\end{array}$ & $\begin{array}{c}\text { BBO\DE\rand } \backslash 1 \\
\text { And } C R=0.5\end{array}$ & $\begin{array}{c}\text { BBO\DE\rand12 } \\
\text { And } C R=0.8\end{array}$ & BBO\DE\L \\
\hline Rosenbrock & 2.341 & 1.847 & 4.671 & 6.441 & 1.961 \\
\hline Beale & 2.873 & 1.803 & 4.789 & 6.348 & 1.197 \\
\hline Booth & 2.746 & 1.934 & 5.75 & 6.474 & 1.716 \\
\hline Branin & 2.866 & 1.777 & 4.912 & 6.177 & 1.934 \\
\hline Easom & 2.894 & 1.925 & 5.485 & 6.294 & 1.993 \\
\hline Boh1 & 2.786 & 1.941 & 4.807 & 6.42 & 1.93 \\
\hline Boh2 & 2.738 & 1.989 & 4.794 & 6.998 & 1.822 \\
\hline Boh3 & 2.346 & 1.755 & 5.649 & 6.291 & 1.927 \\
\hline Hump & 3.011 & 1.992 & $\begin{array}{l}5.748 \\
\end{array}$ & 7.407 & 1.990 \\
\hline Matyas & 2.785 & 1.746 & 4.776 & 6.294 & 1.798 \\
\hline
\end{tabular}



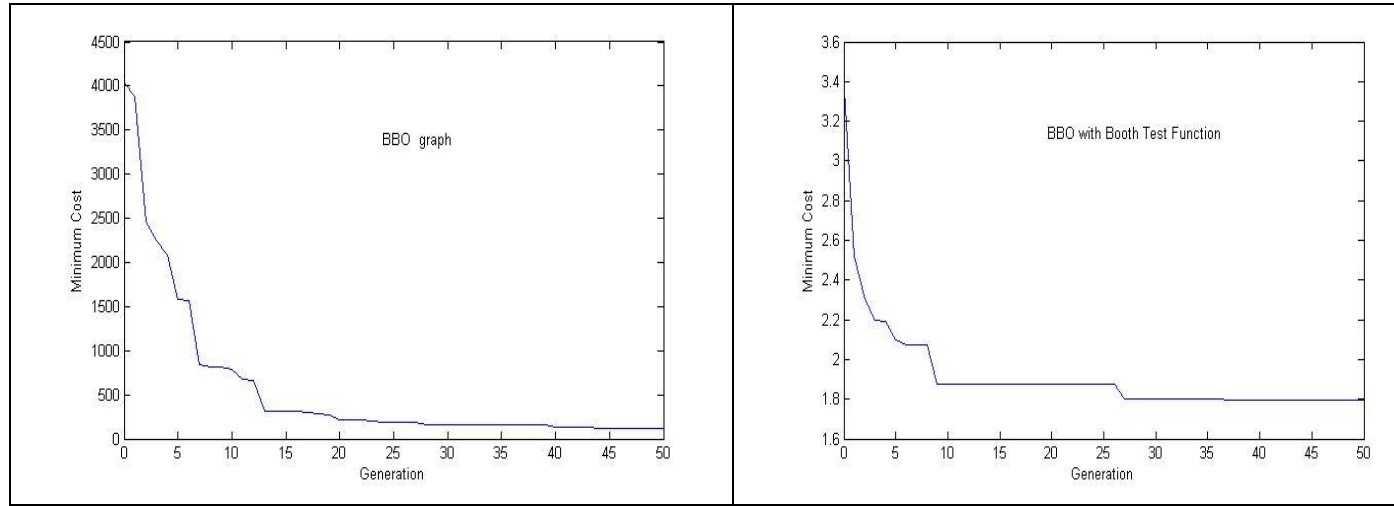

Figure 1. Convergence Characteristics of BBO for Rosenbrock and Booth Test Functions

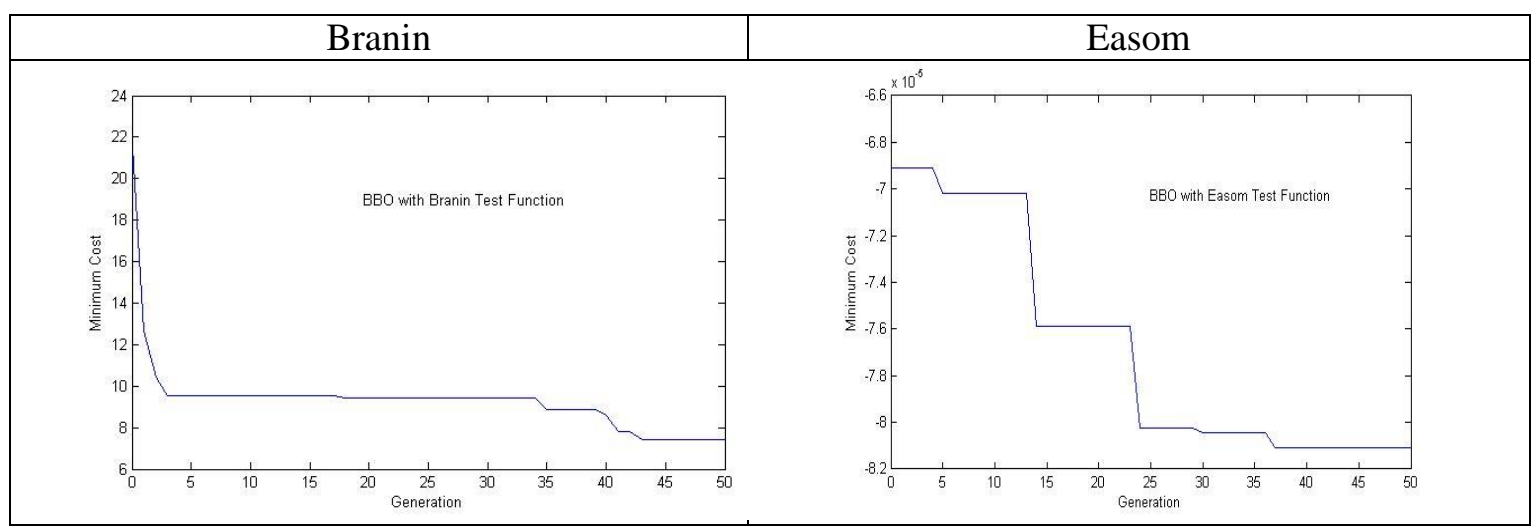

Figure 2. Convergence Characteristics of BBO for Branin and Easom Test Functions

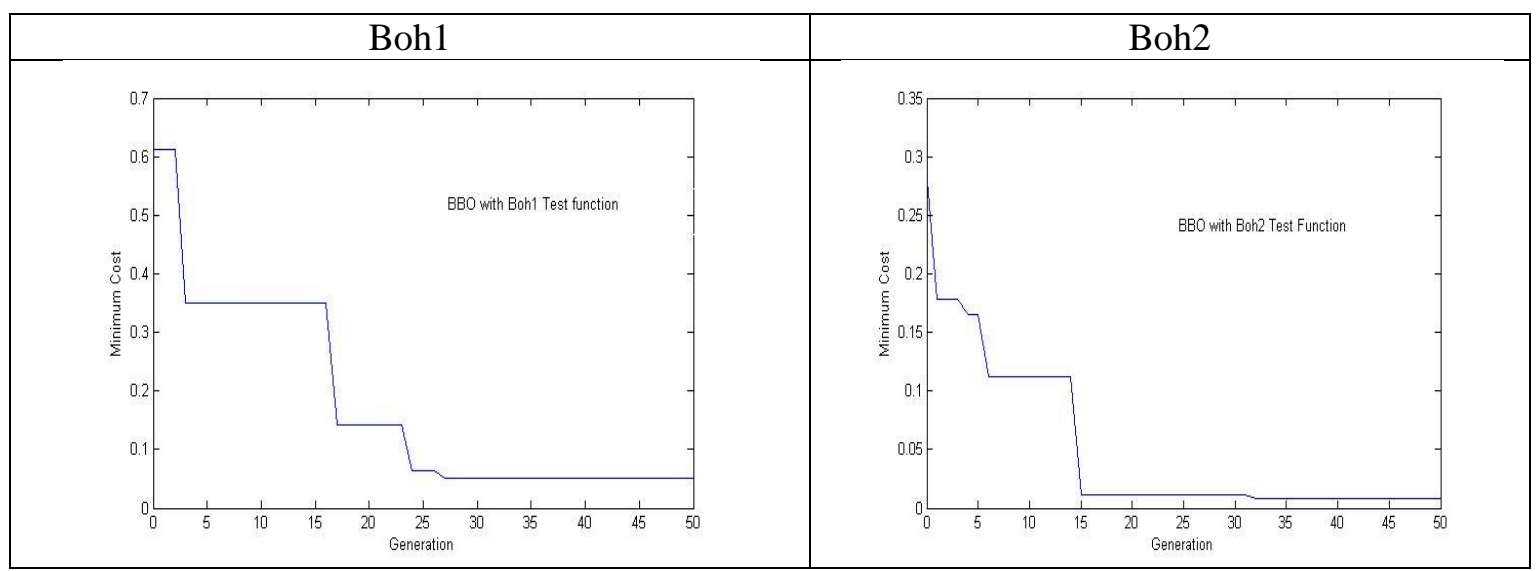

Figure 3. Convergence Characteristics of BBO for Boh1 and Boh2 Test Functions 


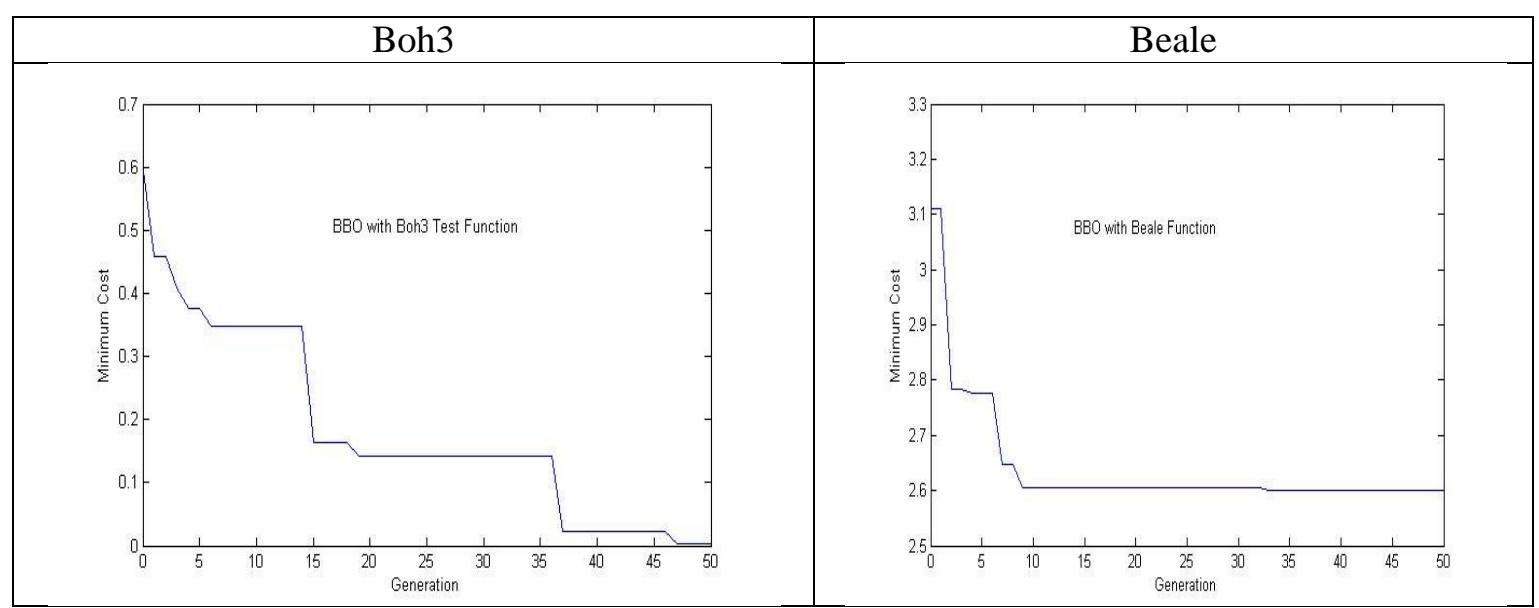

Figure 4. Convergence Characteristics of BBO for Boh3 and Beale Test Functions

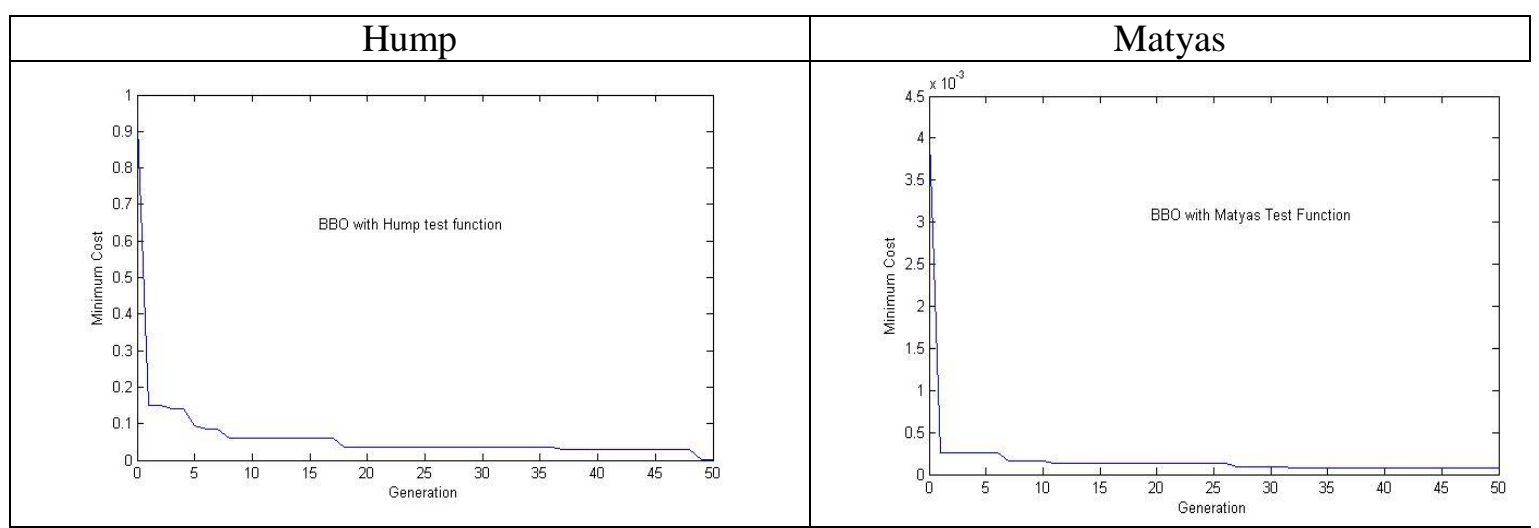

Figure 5. Convergence Characteristics of BBO for Hump and Matyas Test Functions

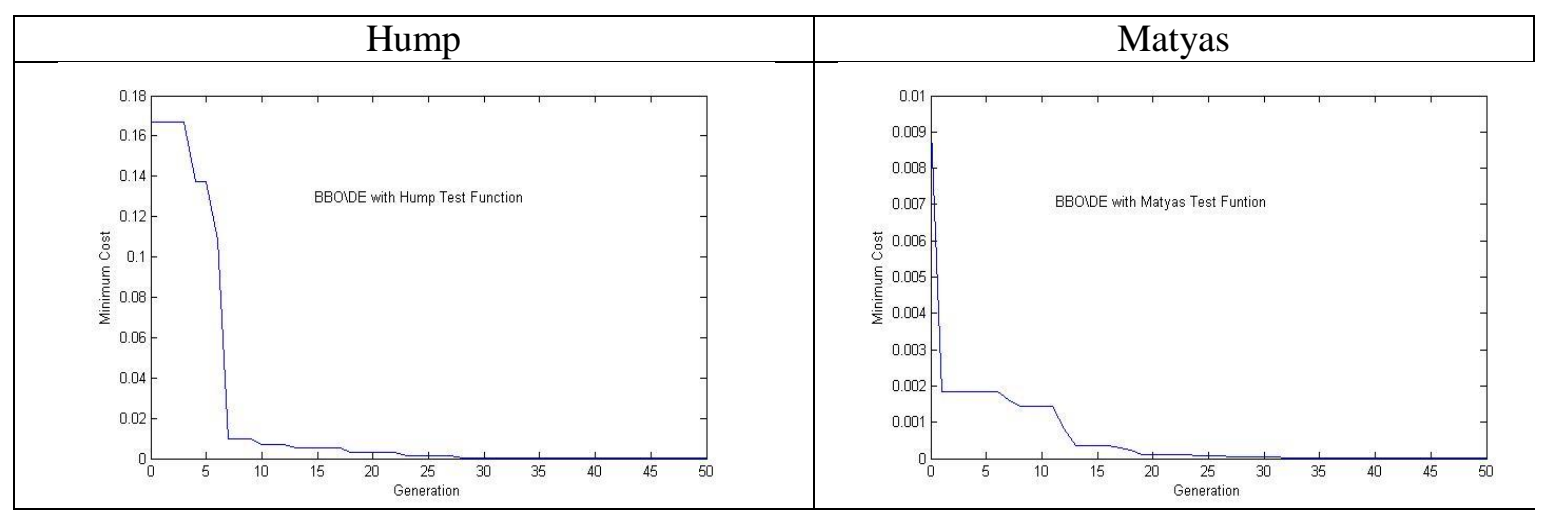

Figure 6. Convergence Characteristics of BBO\DE\rand $\backslash 1$ for Hump and Matyas Test Functions and $\mathrm{CR}=0.01$ 


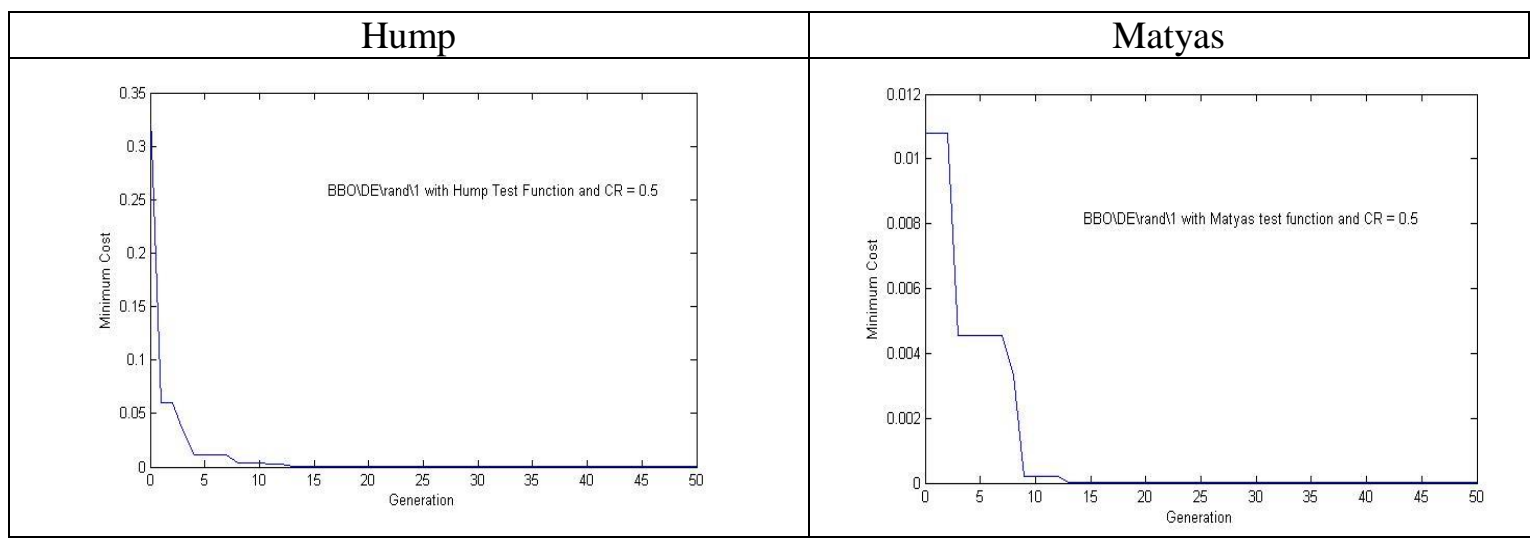

Figure 7. Convergence Characteristics of BBO\DE\rand $\backslash 1$ for Hump and Matyas Test Functions and $\mathrm{CR}=0.5$

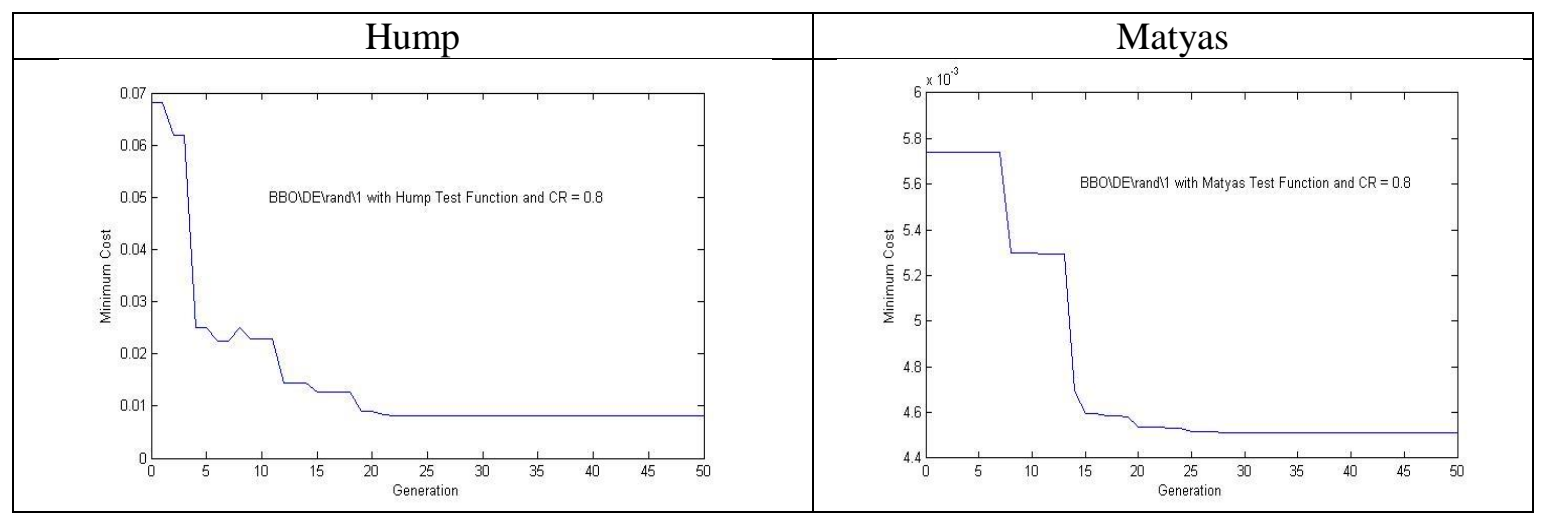

Figure 8. Convergence Characteristics of BBO\DE\rand $\backslash 1$ for Hump and Matyas Test Functions and $\mathrm{CR}=0.8$

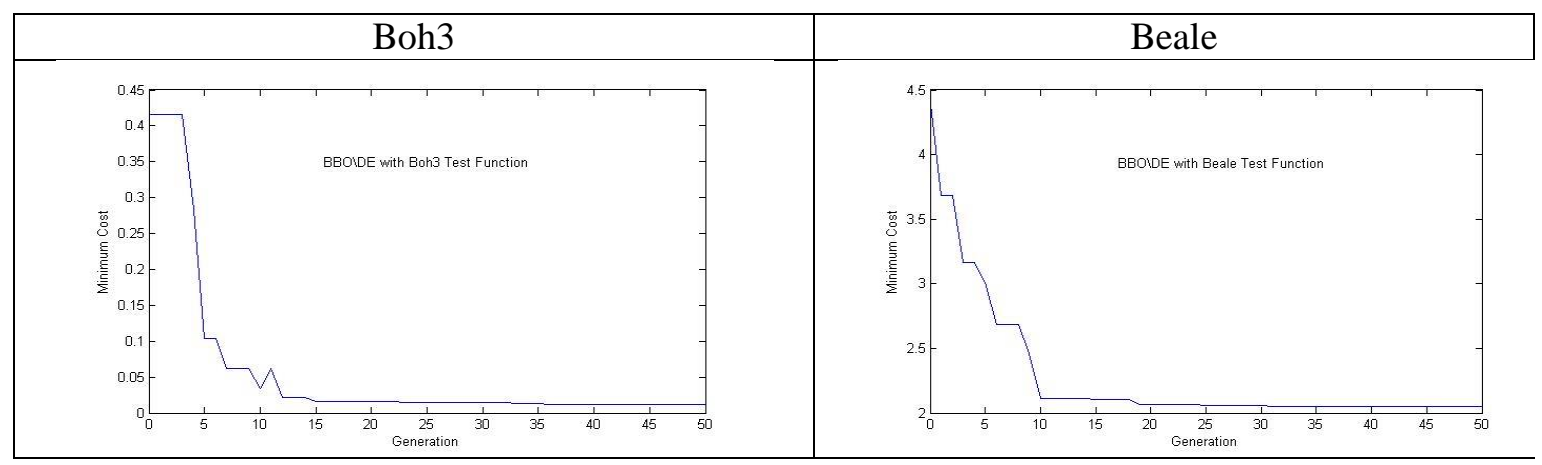

Figure 9. Convergence Characteristics of BBOIDE\rand $\backslash 1$ for Boh3 and Beale Test Functions and $\mathrm{CR}=\mathbf{0 . 0 1}$ 


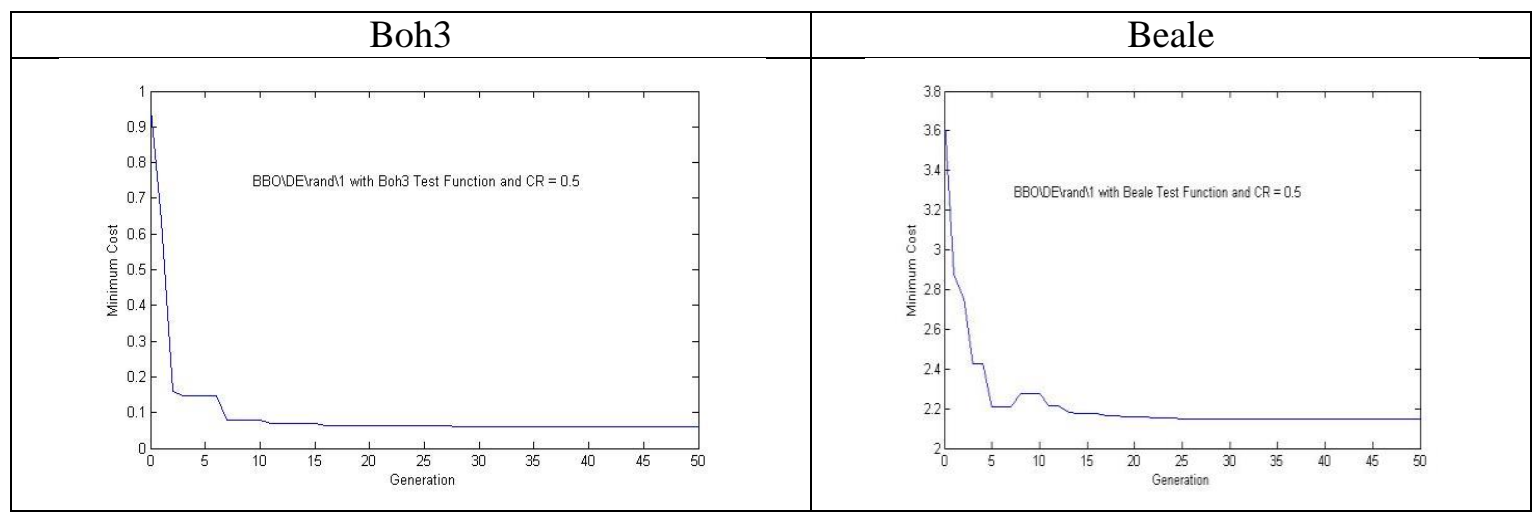

Figure 10. Convergence Characteristics of BBOLDE\rand 11 for Boh3 and Beale Test Functions and $\mathrm{CR}=\mathbf{0 . 5}$

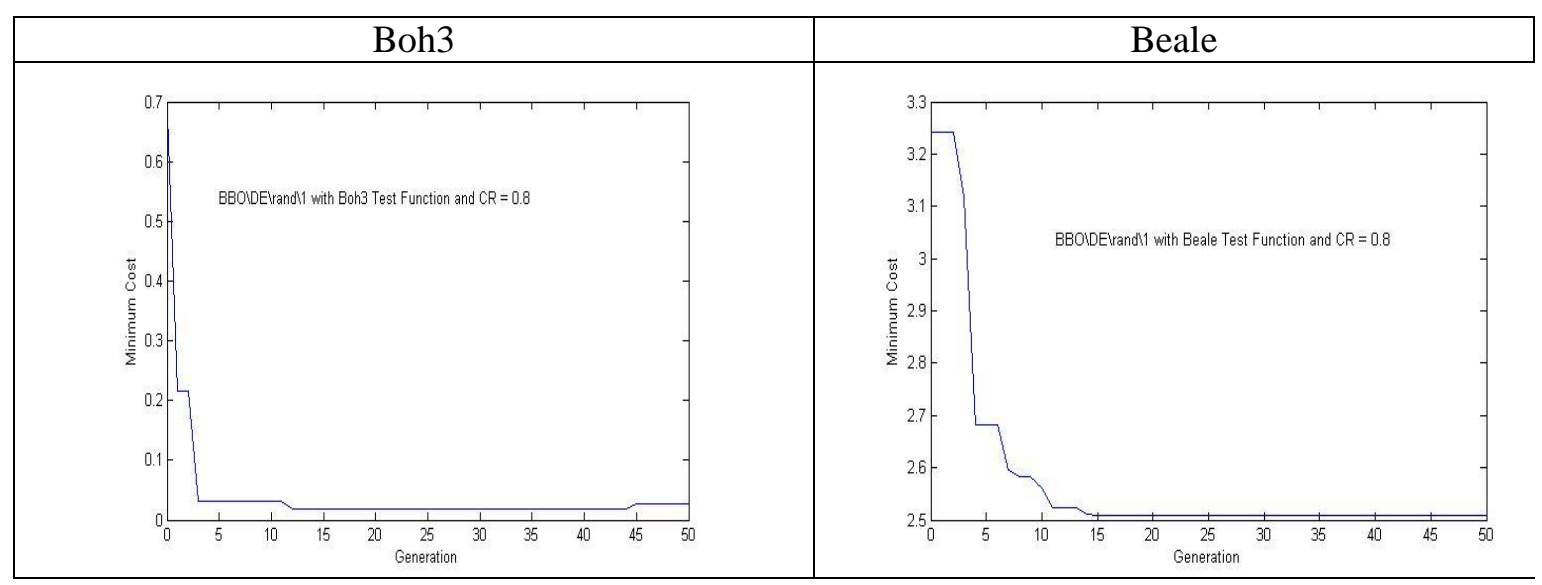

Figure 11. Convergence Characteristics of BBO\DE\rand $\backslash 1$ for Boh3 and Beale Test Functions and $\mathrm{CR}=\mathbf{0 . 8}$

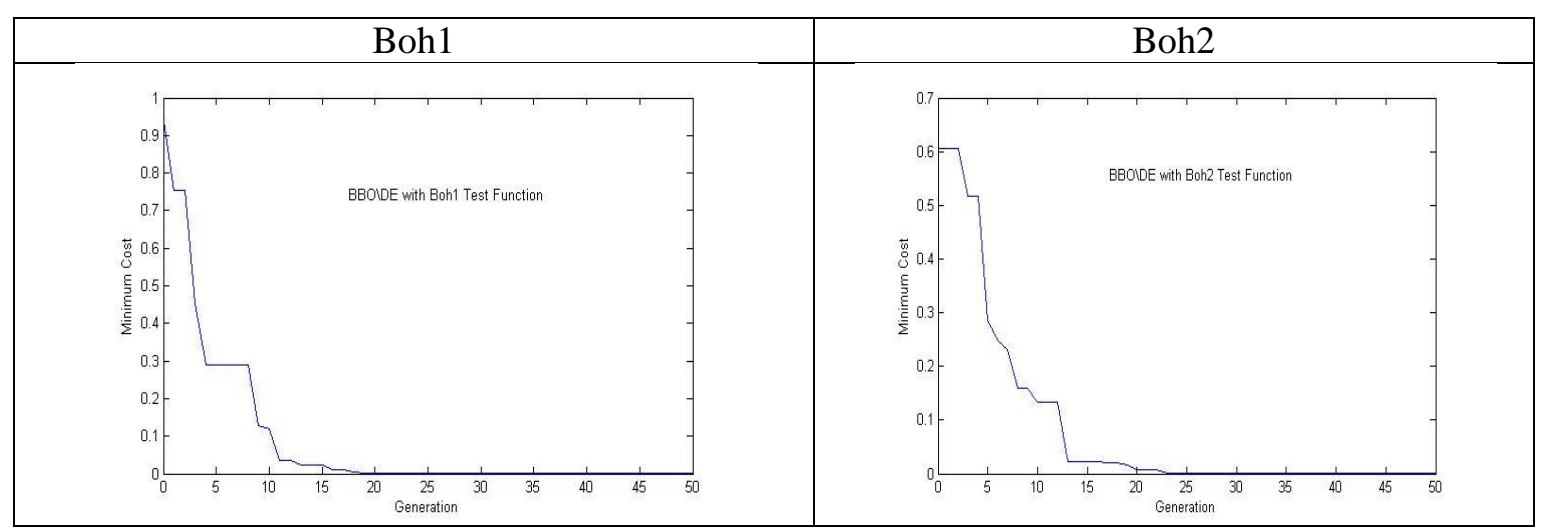

Figure 12. Convergence Characteristics of BBO\DE\rand $\backslash 1$ for Boh1 and Boh2 Test Functions and $\mathrm{CR}=\mathbf{0 . 0 1}$ 


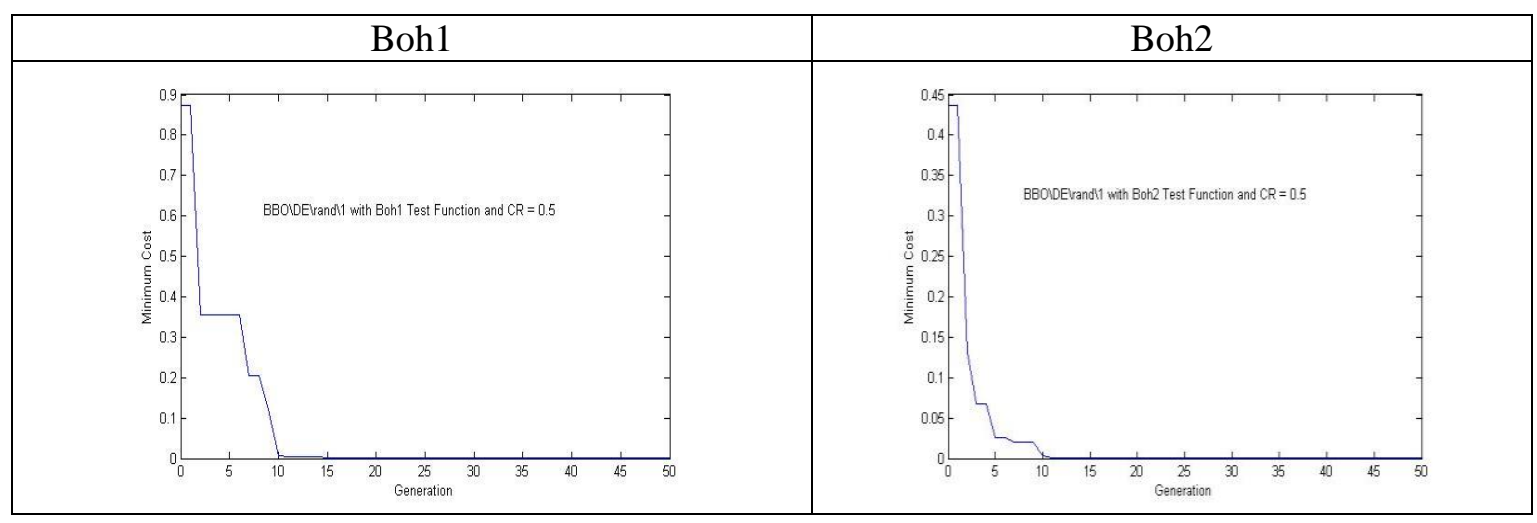

Figure 13. Convergence Characteristics of BBO \DE\rand $\backslash 1$ for Boh1 and Boh2 Test Functions and $\mathrm{CR}=0.5$

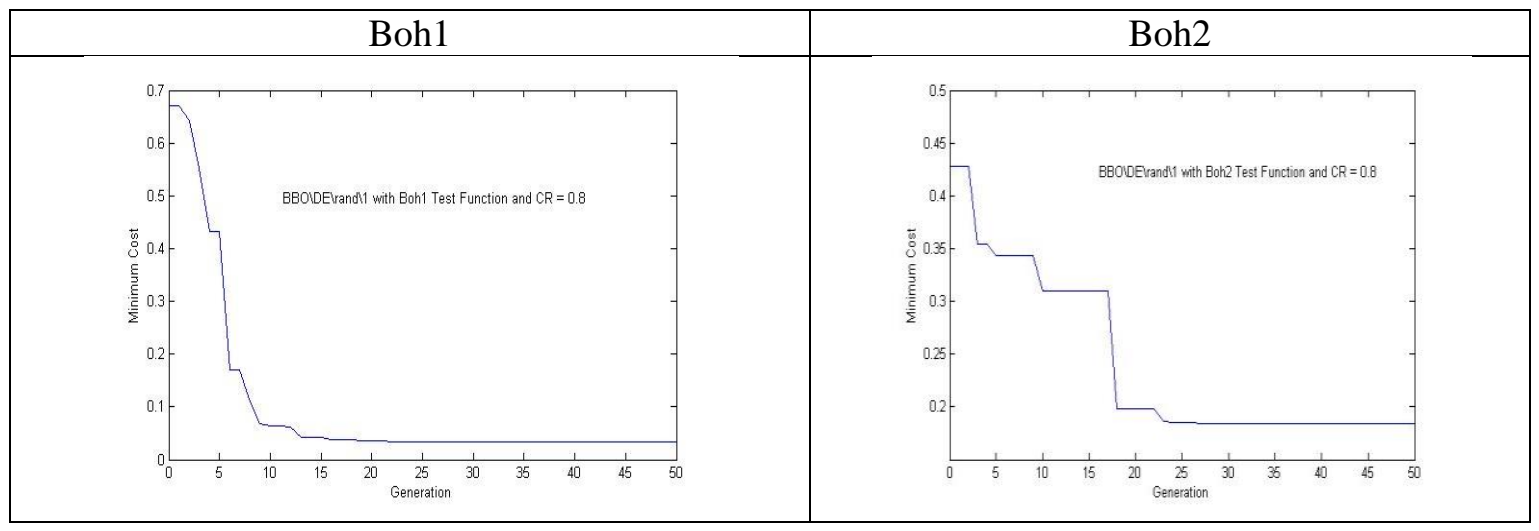

Figure 14. Convergence Characteristics of BBO $\backslash D E \backslash$ rand $\backslash 1$ for Boh1 and Boh2 Test Functions and $\mathrm{CR}=\mathbf{0 . 8}$

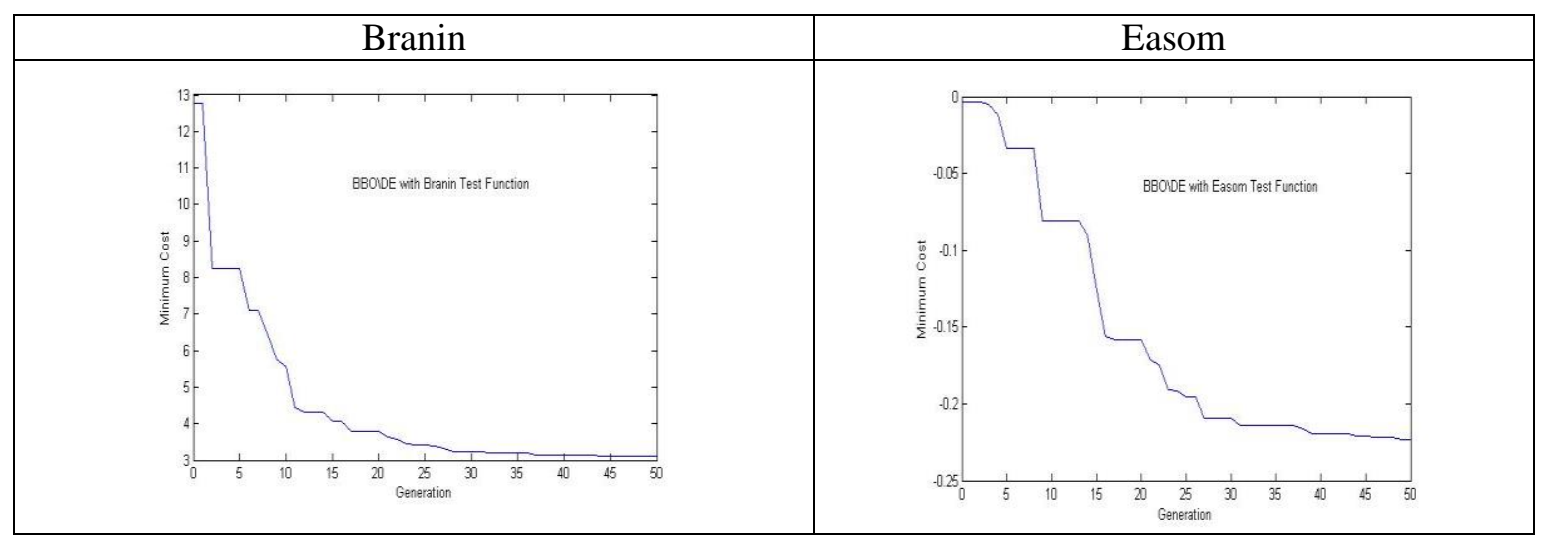

Figure 15. Convergence Characteristics of BBOIDE\rand $\backslash 1$ for Branin and Easom Test Functions and $\mathrm{CR}=0.01$ 


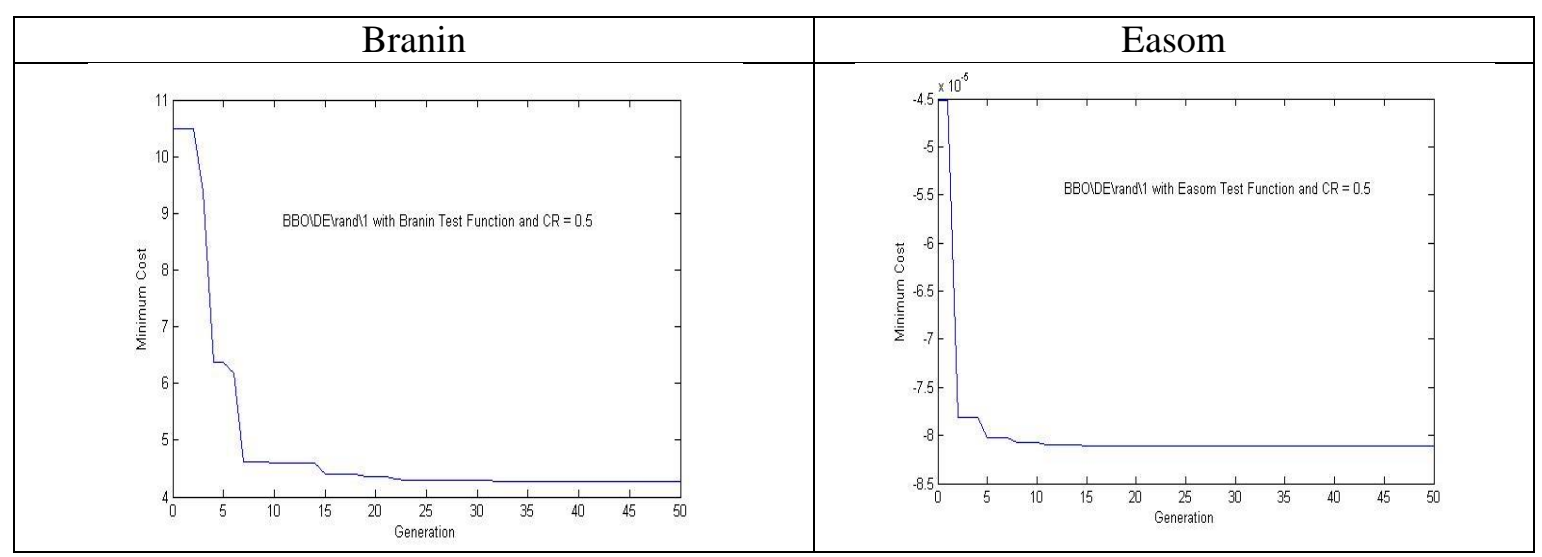

Figure 16. Convergence Characteristics of BBO $\backslash D E \backslash$ rand $\backslash 1$ for Branin and Easom Test Functions and $\mathrm{CR}=0.5$

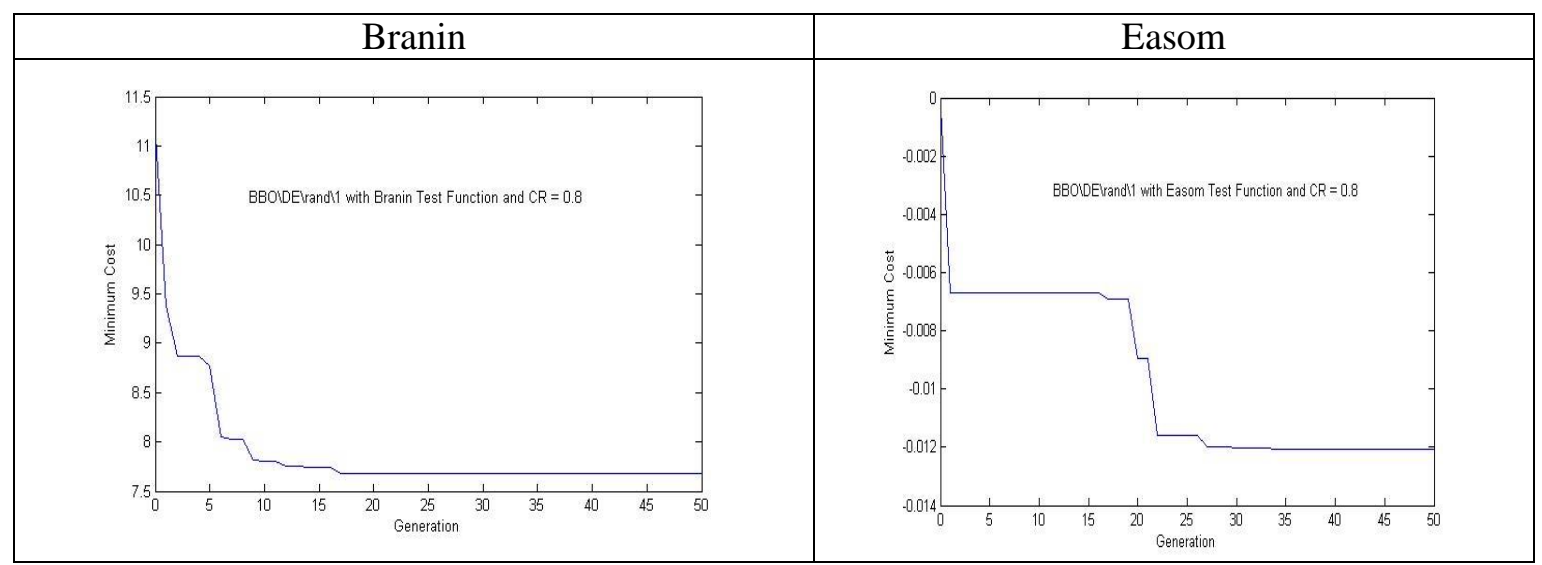

Figure 17. Convergence Characteristics of BBO $\mid D E \backslash$ rand $\backslash 1$ for Branin and Easom Test Functions and $\mathrm{CR}=\mathbf{0 . 8}$

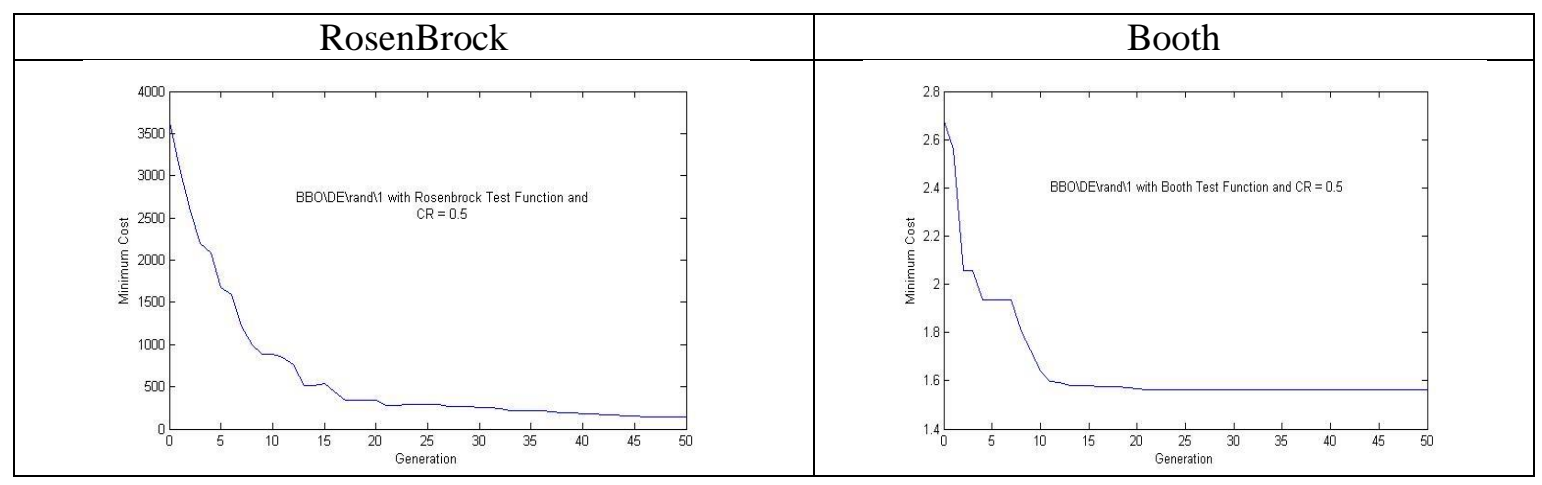

Figure 18. Convergence Characteristics of BBOIDE\rand $1 \mathbf{1}$ for Rosenbrock and Booth Test Functions and $C R=0.5$ 


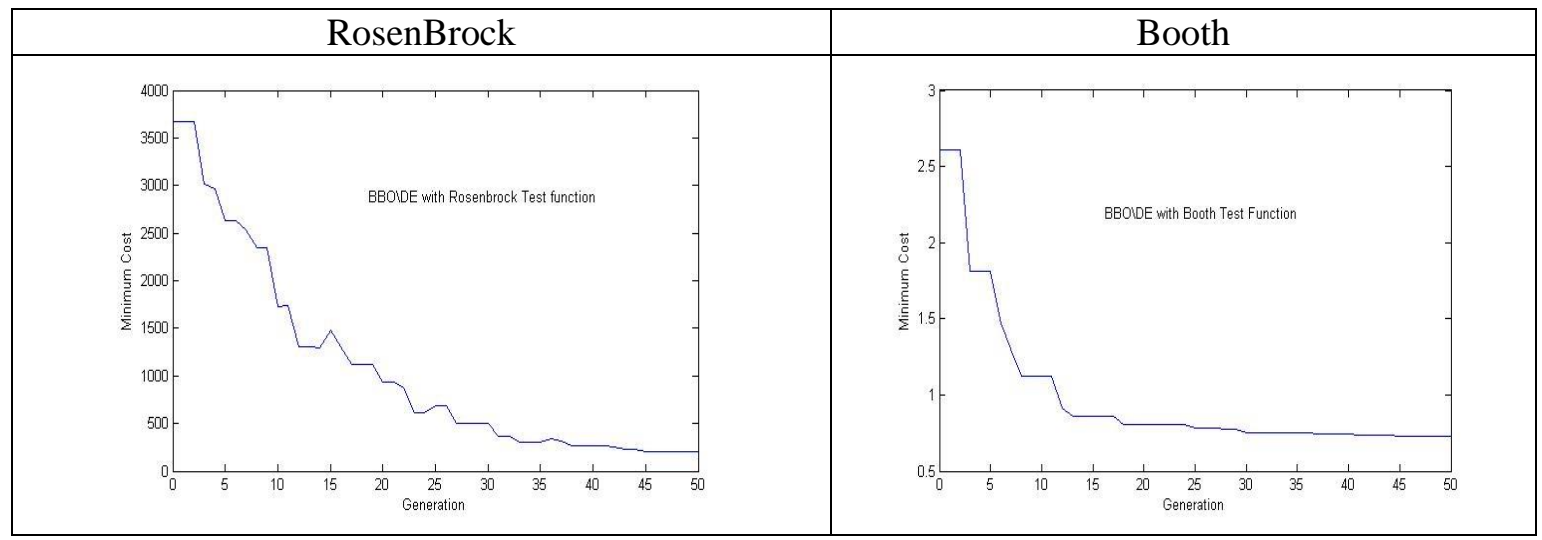

Figure 19. Convergence Characteristics of BBO $\backslash D E \backslash$ rand 1 for Rosenbrock and Booth Test Functions and $\mathrm{CR}=0.01$

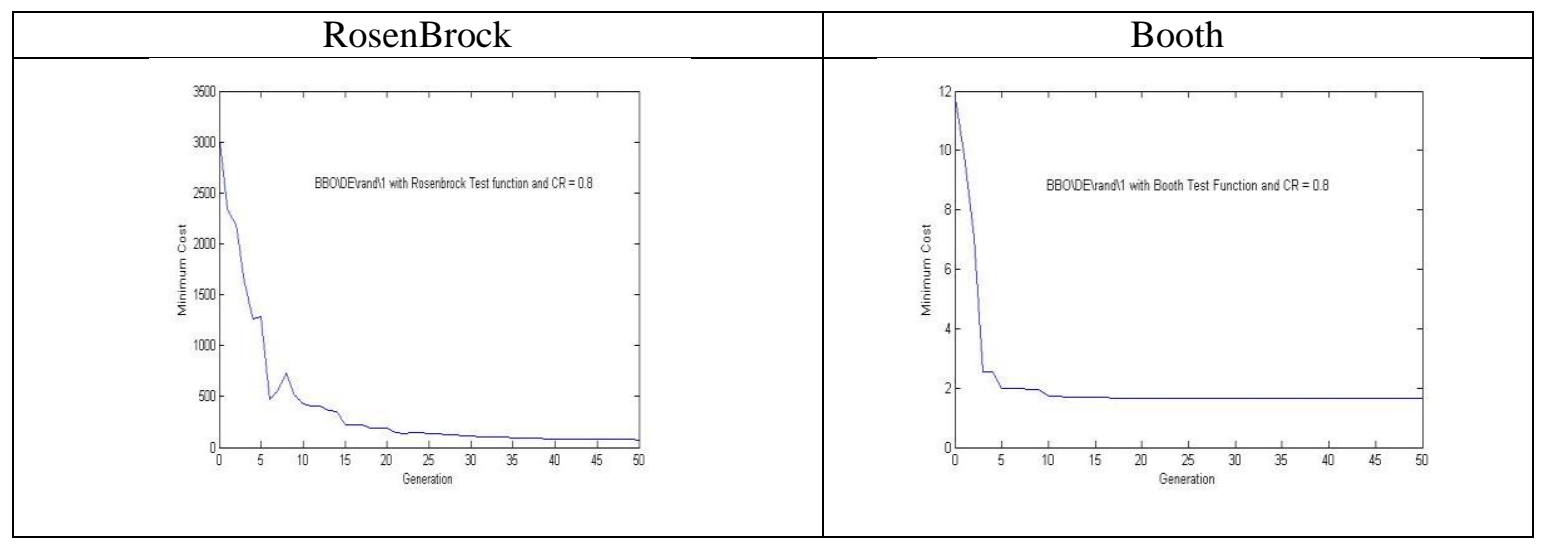

Figure 20. Convergence Characteristics of BBO $\backslash D E \backslash$ rand $\backslash 1$ for Rosenbrock and Booth Test Functions and $\mathrm{CR}=0.8$

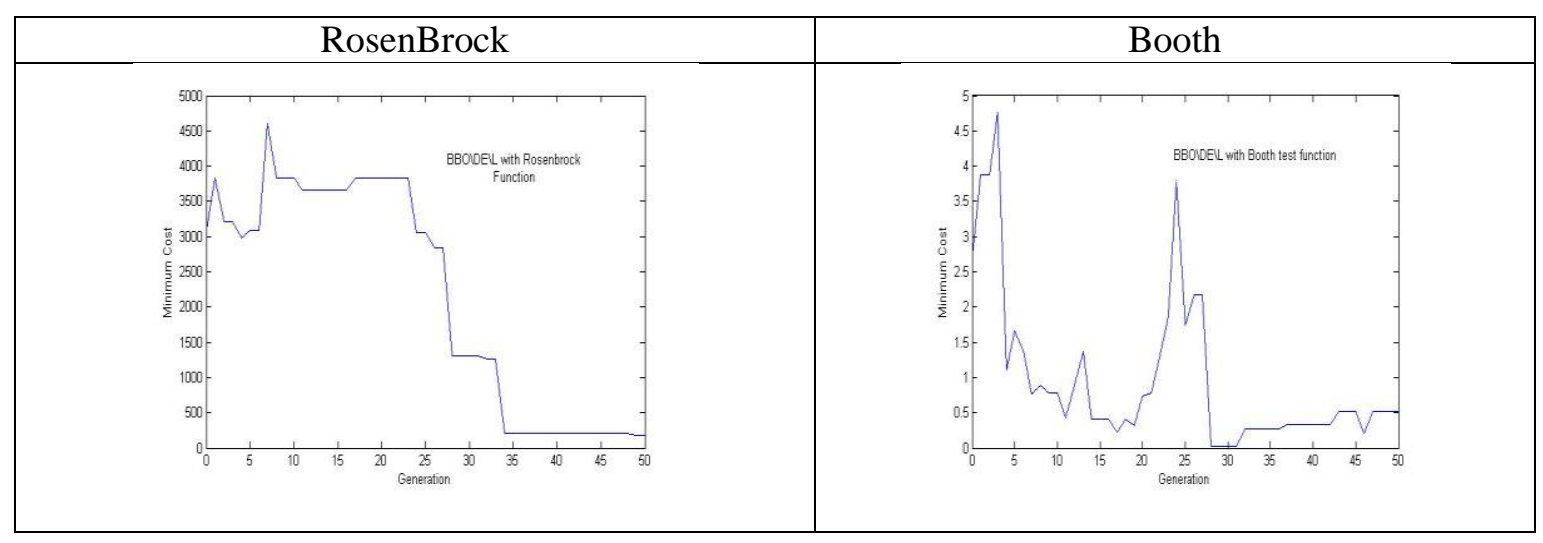

Figure 21. Convergence Characteristics of BBO $\backslash D E \backslash L$ for Rosenbrock and Booth Test Functions 


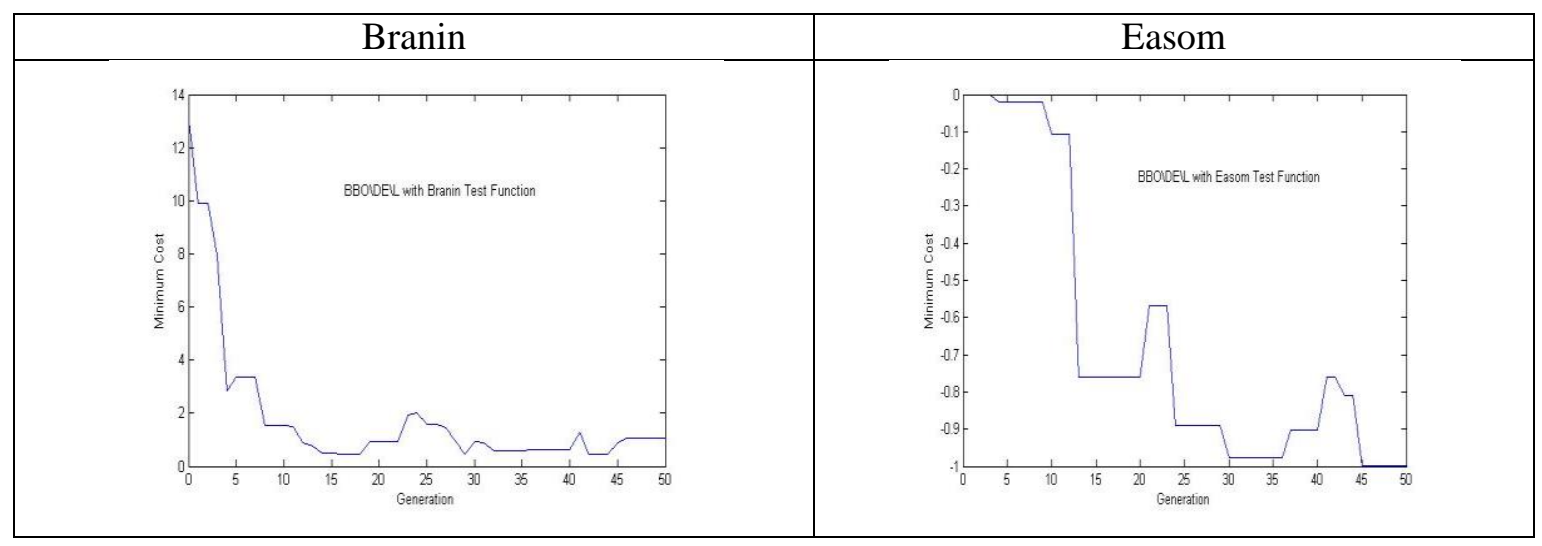

Figure 22. Convergence Characteristics of BBOIDE $L$ for Branin and Easom Test Functions

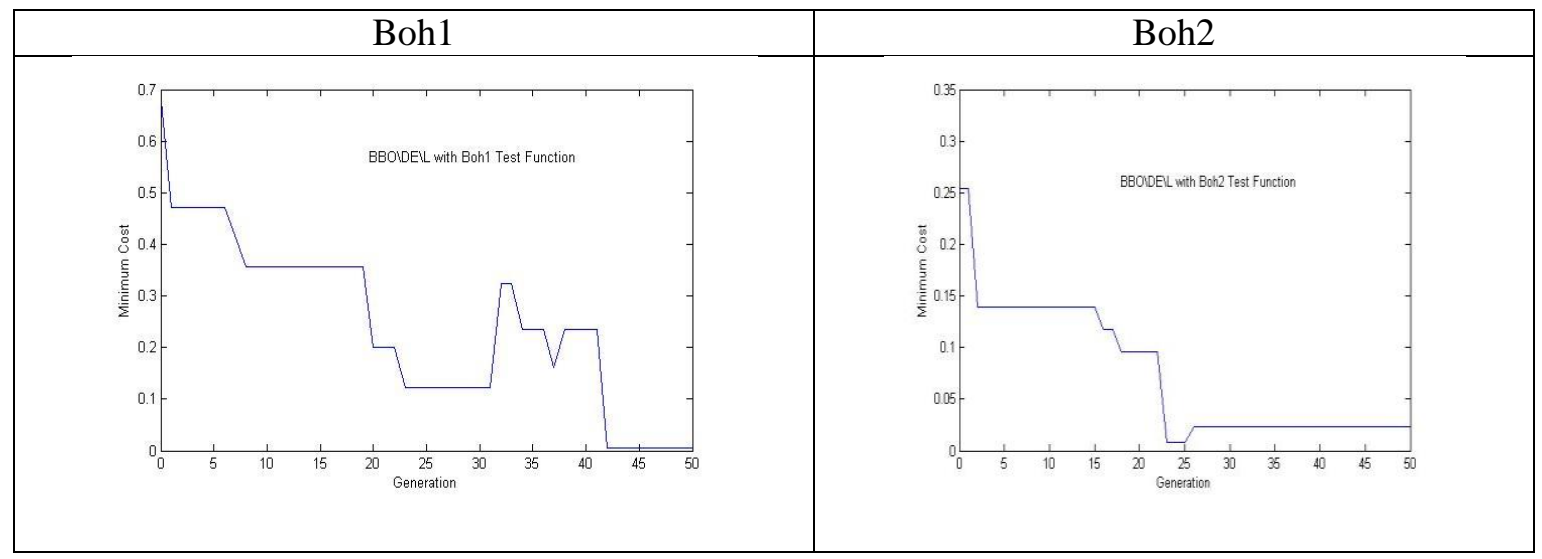

Figure 23. Convergence Characteristics of BBO $\mid D E \backslash L$ for Boh1 and Boh2 Test Functions

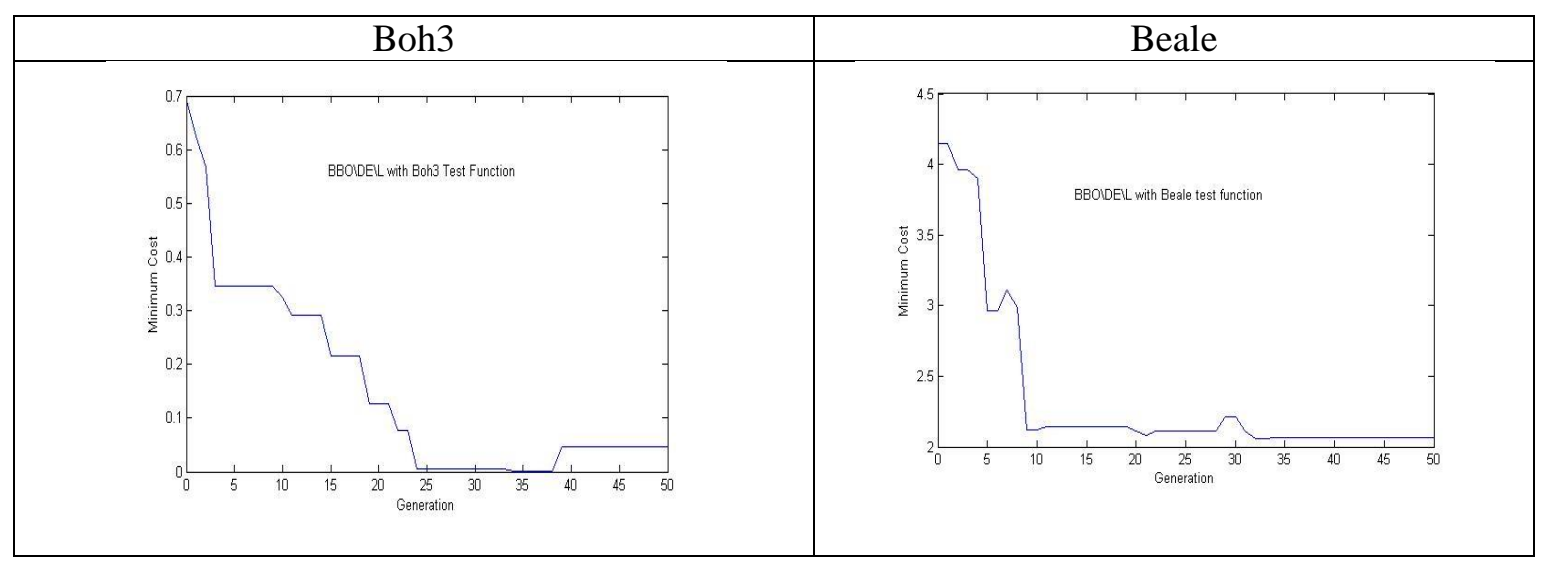

Figure 24. Convergence Characteristics of BBO $\backslash D E \backslash L$ for Boh3 and Beale Test Functions 


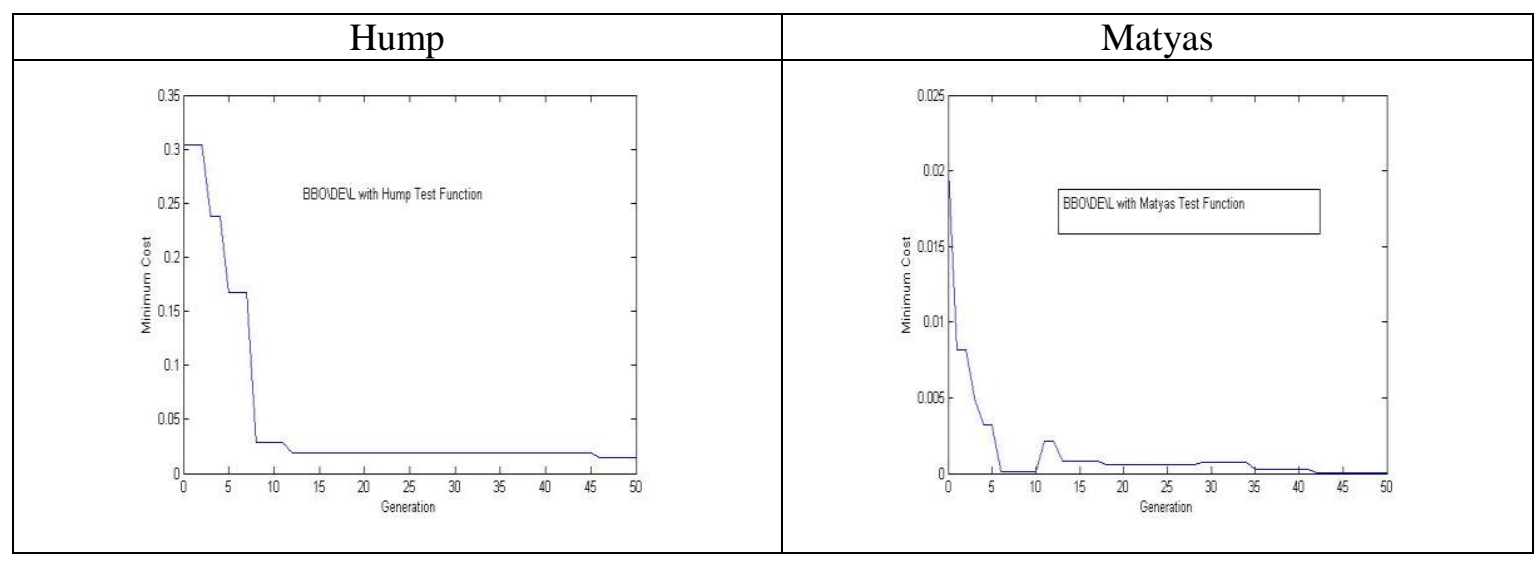

Figure 25. Convergence Characteristics of BBOIDE $\backslash L$ for Hump and Matyas Test Functions

\section{Conclusion and Future Scope}

This paper has been devoted to the modification of DE\BBO to improve its limitation. DE\BBO with simple mutation technique was developed to dominate the performance of BBO. From the results, it can be seen that DE\BBO\rand 1 takes more time to converge for higher values of crossover rate. Example, When $\mathrm{CR}=0.8$, convergence time for DE\BBO\rand $\backslash 1$ using Rosenbrock test function is 6.441 which is much higher than convergence time of $\mathrm{BBO}$. Thus, this implies that crossover rate influences performance of DE\BBO\rand $\backslash 1$. Limitation of DE\BBO\rand $\backslash 1$ has been improved by introducing Local search mutation which uses the variable crossover rate for all generations and improved scheme has been named as DE $\backslash B B O L L$. In DE $\backslash B B O L L$, crossover value also tends to the upper limit but it does not affect the convergence time. The performance has been tested by using different ten test functions which shows that DEIBBOLL outperforms $\mathrm{BBO}$ and DELBBOlrand $\backslash 1$ in terms of convergence speed and quality of solution.

Overall, it can be concluded that purposed DE BBBOL algorithm dominates the performance of both $\mathrm{BBO}$ and $\mathrm{DE} \backslash \mathrm{BBO} \backslash \mathrm{L}$ and gives quality results.

A lot of future work can be done. Applicability of the purposed algorithm can be checked for various applications. Further changes can be done in DE\BBOLL by using the restart mechanism. Comparative study can be done with other existing algorithms to check the performance of DE $\ B B O L$ L. Impact of population size, population dimension, and generations can be studied for DEIBBOLL. Performance of modified DELBBOLL can be checked on other test functions and the results can be compared.

\section{References}

[1] R. Storn and K. V. Price, "Differential evolution- A simple and efficient adaptive scheme for global optimization over continuous spaces", Technical Report TR-95-012, ICSI, (1995).

[2] R. Storn and K. V. Price, "Differential Evolution- a simple and efficient heuristic for global optimization over continuos spaces", Journal of Global Optimization, vol. 11, no. 4, (1997), pp. 341-359.

[3] R. Storn, K. V. Price and J. Lampinen, "Differential Evolution- A Practical Approach to Global Optimization”, Springer, Berlin, (2005).

[4] D. Swagatam, A. Ajith and K. Uday, "Differential Evolution Using a Neighborhood-based Mutation Operator", (2007).

[5] D. Simon, "Biogeography-based optimization", IEEE Transactions on Evolutionary Computation, vol. 12, no. 6, (2008), pp. 702-713.

[6] M. Ergezer, D. Simon and D. Du, "Oppositional Biogeography-Based Optimization”, Proceedings of IEEE International Conference on Systems, Man, and Cybernetics San Antonio, TX, USA, (2009).

[7] W. Gong, Z. Cai, C. X. Ling and H. Li, "A real coded Biogeography based optimization with mutation", Applied Mathematics and Computation, vol. 216, (2010), pp. 2749-2758. 
[8] A. Bhattacharya and P. K. Chattopadhyay, "Hybrid Differential Evolution With Biogeography-Based Optimization for Solution of Economic Load Dispatch", IEEE TRANSACTIONS ON POWER SYSTEMS, vol. 25, no. 4, (2010).

[9] S. Kanoongo and P. Jain, "Blended Biogeography Based Optimization for different economic load dispatch problem", IEEE Canadian Conference on Electrical and Computer Engineering (CCECE), (2012).

[10] A. de Marsil, C, e Silva, L, dos S. Coelho and L. Lebensztajn, "Multiobjective Biogeography- Based Optimization Based on predator-Prey Approach", IEEE TRANSACTIONS ON MAGNETICS, vol. 48, no. 2, (2012).

[11] D. Simon, M. G. H. Omran and M. Clerc," Linearized Biogeography-Based Optimization with Reintialization and Local search", Information Sciences, vol. 267, (2014), pp. 140-157.

[12] H. Ma, D. Simon, M. Fei, X. Shu and Z. Chen, "Hybrid Biogeography-Based evolutionary algorithms", Engineering Applications of Artificial Intelligence, vol. 30, (2014), pp. 213-224.

[13] A. W. Mohamed, "RDEL: Restart Differential Evolution algorithm with Local Search Mutation for global numeric optimization", Egyptian Informatics Journal, (2014). 